\title{
EDITORIAL
}

\section{The role of psychiatrists in developing the skills of dementia care workers}

\author{
Julian Mason \& Adetokunbo Adeshina
}

\begin{abstract}
Julian Mason is a consultant old age psychiatrist working in Reading He leads a multidisciplinary team to run the Understanding Dementia course for Berkshire Healthcare NHS Foundation Trust. This provides training programmes in care homes and domiciliary services with which the Trust has an active clinical link. Adetokunbo Adeshina is an ST6 in old age psychiatry with East London NHS Foundation Trust. He is interested in carer support and maintaining high-quality day-to-day care for people with dementia. Correspondence Dr Julian Mason, Hazelwood, Prospect Park Hospital, Honey End Lane, Reading RG30 4EJ, UK. Email: jules.mason@ berkshire.nhs.uk
\end{abstract}

a. The case of $\mathrm{Mr} P$ is fictitious but representative of a very typical clinical problem.

\begin{abstract}
SUMMARY
A recommendation of the UK's National Dementia Strategy is to develop the skills of the care workers who provide day-to-day care for people with dementia. On the basis of a systematic review of the literature, we suggest evidence-based areas in which the skills of care workers can be developed to reduce the incidence of difficult behaviour and the use of antipsychotic medication in dementia. We discuss core features of carer training, education and practice. Psychiatrists involved in the training of carers can teach new skills to carers. Psychiatrists in community mental health teams can, through leadership and clinical liaison, reinforce and enable these skills in care homes, domiciliary services and in-patient settings serving people with dementia.
\end{abstract}

\section{DECLARATION OF INTEREST}

None.

\section{Clinical vignette ${ }^{\mathrm{a}}$}

$\mathrm{Mr} \mathrm{P}$ is an 88-year-old widower with moderately advanced mixed dementia. He lives in a 'dementia specialist' residential home and needs regular assistance with his personal care. His general practitioner (GP) referred him to the local community mental health team for older adults because of his resistance to personal care - he had hit two care workers with a baton when they tried to help him. The referral letter explained that a low dose of haloperidol had not improved Mr P's difficult behaviour and the GP wanted an expert opinion before increasing the dose.

The consultant psychiatrist and a community psychiatric nurse (CPN) visited the home the day after the referral. On the wall of the entrance hall were the framed certificates indicating staff attendance at a dementia awareness day. They learnt that $\mathrm{Mr} \mathrm{P}$ had been born and raised in India, where his father had been a colonel in the British army. The baton had been part of his father's military uniform and he was very proud of this family heirloom. The care workers who had been struck with the baton were from Asia and the Philippines. The manager of the care home, who had been in the post for only a few weeks, explained that although there was regular turnover of care staff, the current carers were quick and efficient with care and had been taught always to approach Mr P from the front, speaking to him slowly and loudly.

On the advice of the CPN and psychiatrist, the carers changed their style of approach during personal care: they slowed down the delivery of care, focusing on rapport and taking time to engage $\mathrm{Mr} \mathrm{P}$ in the process; they sought his permission to start dressing, undressing or washing him; and they approached him from the front, smiling and giving him time to respond to prompts. As long as his beloved baton was treated with respect and placed carefully on a clean surface, $\mathrm{Mr} \mathrm{P}$ was content to hand it over during personal care. His hearing was well preserved and it turned out that the carers did not need to speak loudly to him. The situation improved, the haloperidol was stopped and $\mathrm{Mr} \mathrm{P}$ continued to be cooperative with care.

The manager of care home sent the CPN a copy of the learning objectives of the dementia awareness training that all of his senior staff attended. In the accompanying letter he asked whether there was anything else that should be taught to improve dementia care in the home. The CPN showed the letter to the psychiatrist, who was always challenging colleagues about the evidence for their interventions, and asked for help in preparing a response. This article provides the information on which such a response could be based.

Many organisations in the UK, including Social Services, the National Health Service (NHS), care homes and domiciliary care companies, employ low-paid, high-turnover staff to care for people with dementia (Banazak 2000). It is estimated that these employees provide $80 \%$ of purchased care for people who have the illness (Mathews 1997; Matteson 1997; McCallion 1999). Regardless of their experience in dementia care, these staff are usually expected to take on the care of patients immediately, hopefully picking up necessary skills on the job or from colleagues and variable training opportunities (Lintern 2000). Many people with dementia are living in care homes that are not specialised and this lack of appropriate skills contributes to the prevalence of the behavioural and psychological symptoms of dementia and increased use of antipsychotic medication. Care workers are keen to be trained and it is frequently 
because of lack of leadership that carers are not applying core skills (Smyer 1992; Rosen 2002).

It is primarily the responsibility of the employing organisation to ensure that its dementia care workers are trained. However, old age psychiatrists also have an important role, as leaders, external educators, experts and local dementia champions, in setting standards and reinforcing and enabling good dementia care. Senior psychiatrists who work in a locality for a number of years develop relationships and have local knowledge about care homes and other care providers. Working within community mental health teams, they can contribute significantly to the promotion of care skills (Proctor 1999; Featherstone 2004). They should be familiar with the evidence-based core skills that care workers should have before they take on the care of people with dementia.

A body of research literature identifies care skills that make a difference and gives advice on how best to apply them. Admittedly, most of the studies are of limited quality and from a narrow academic perspective (Livingston 2005; Kuske 2007). However, taken as a whole, they describe the training strategies, methods and core skills that every paid carer should be taught because they have been shown to make a difference. Although some psychiatrists give seminars or teach on courses, this predisposing stage of education usually falls to other professionals. The main task of most psychiatrists in this area is to promote such educational activity and ensure that the stages of reinforcing and enabling take place. Without these three stages (Box 1, and discussed below), classroom teaching is largely ineffective (MonizCook 1997, 1998, 2000; Featherstone 2004).

\section{Systematic review}

A systematic review revealed 33 primary studies that aimed to develop care skills for paid dementia carers (brief outlines of these studies are given in online Table DS1). At best, they provide level 4 evidence, quasi-experimental controlled or

\section{BOX 1 Three stages of education}

- The predisposing stage: the communication or dissemination of information designed to modify an individual's knowledge, beliefs and attitudes

- The enabling stage: ensuring that conditions and resources in the work environment allow individuals to implement the skills they have just learnt

- The reinforcing stage: giving cues or reminders to implement new skills before-and-after studies (Centre for Evidence Based Medicine 2009). Taking into consideration the difficulties of designing experimental research into educational interventions, they form the best available evidence of the knowledge and skills dementia care workers should have and how best to train them (Maas 1994; Grol 2003; Draper 2004).

The studies describe a wide variety of educational interventions and use diverse terminology, but all are trying to improve the day-to-day care of people with dementia. After careful repeated reading, discussion, textual and thematic analysis, we identified the key elements of skills training for which there is evidence of success. Although all of the studies took place in care homes, we believe that the principles set out here apply to dementia care in other settings, such as domiciliary care companies and in-patient wards.

\section{Eleven core features of good dementia care training}

Eleven core features of training for dementia care workers emerged from the studies: three relate to strategy, one to training methods and seven to attitudes, knowledge and skills (Box 2). In our summary of each of these, we do not refer to any particular care or therapeutic models. All the studies employed these features to some extent in their interventions to develop care skills and those that demonstrate their value most clearly are cited at the end of each section.

These features should inform psychiatrists and CPNs such as those in the vignette of $\mathrm{Mr} \mathrm{P}$, trying to prevent behavioural and psychological symptoms of dementia and reduce the use of antipsychotics (Matteson 1997; Middleton 1999; Testad 2005). They should equally guide the manager of Mr P's care home on an overall approach to developing and sustaining care skills in all his staff (MonizCook 1997, 1998, 2000).

\section{Strategy}

\section{Valuing dementia care workers}

Every organisation that provides staff, employs staff, commissions their services or supports their work through clinical liaison should acknowledge that the experience of individuals with dementia will be determined by the quality of day-today care provided by these workers. For Mr P, the approach of his carers was contributing to his symptoms. Recognising their own role in improving Mr P's behaviour was essential to reducing his aggression and minimising the use of antipsychotic medication. People with dementia 
BOX 2 Evidence-based approach to developing care skills of front-line dementia care workers: 11 core features

Core features
Strategy
1 Recognition of care workers' key role in determining the
quality of care
2 Long-term commitment of employing organisation to
predisposing the teaching of good practice, and enabling
and reinforcing its application
3 Making dementia care training accessible, e.g. available
to all staff at little or no cost to them and repeated on a
regular basis (for new staff and as a refresher)

Training methods

4 Interactive teaching in small groups, using a variety of techniques to engage attendees, followed by enabling and reinforcement in the workplace

Training content: attitudes, knowledge and skills

5 A positive yet realistic attitude towards dementia

6 Care and care planning focused on each individual

7 Skills necessary to successfully support the personal activities of daily living

\section{Day-to-day communication}

9 Understanding the organic nature of the condition and associated symptoms

10 Non-pharmacological strategies for difficult behaviour, including identification of predisposing factors

11 Reflection on emotional demands and rewards of working with people with dementia

\section{Practical steps for psychiatrists and community mental health teams}

Emphasise to care providers and fellow clinicians the importance of the quality of care Consider and document how particular care skills may be affecting the symptoms and behaviour of individual patients/clients

Encourage care providers to seek training

Be aware of the content of training, so that it can be reinforced during clinical visits At meetings and committees, support educational initiatives

Encourage care providers to train all their staff

Seek out the views of all carers, irrespective of grade

Match teaching to knowledge

Use role-play, drama, activities, dramatic challenge (teacher plays a person with dementia, and care worker has to demonstrate skills appropriate to the person's behaviour) Do not be afraid to test knowledge

Ensure that employers reinforce classroom knowledge in the workplace

Find out whether carers have either a 'nothing can be done' attitude or unrealistic hopes, and steer towards a balance between being positive about reasonable care objectives yet acknowledging the progression of the condition

Invite the key/named care worker to be present at assessments and demonstrate, through your own behaviour, building a relationship with the patient/client

Ask carers about aspects of the individual's life history that can help care planning

Emphasise that assisting well with activities of daily living influences mood, reduces incidence of behavioural and psychological symptoms of dementia and reduces the need for antipsychotics

During assessments, ask carers about dressing, toileting, bathing and hair-washing

Emphasise value of paced communication that is tailored to the individual

Check whether care staff understand what dementia is and the wide variety of symptoms that it causes, and be ready to challenge views such as 'They could do it if they tried'

Ask carefully about factors that precipitate difficult behaviour and check whether the care team have discussed alternative approaches that may reduce their incidence Explain about dangers of antipsychotic medication

When taking collaborative histories from dementia care staff, ask about their emotional reactions to the individuals in their care rely on care workers, and investing time and effort in training carers for their role does improve the quality of care.

It is also important that the influence of the external educators and experts who provide clinical support in places such as nursing or residential homes is positive. Experts such as psychiatrists should listen carefully to carers' accounts of difficulties in providing care, trying to identify any deficits in core skills and their application. Time should be taken with dementia care workers and those who supervise their work to reinforce the skills set out below. Good care practice should be praised. Effective alternatives to poor practice should be suggested. Care workers should be involved in care planning and deciding how best to implement changes necessary to each individual's care.

\section{Key studies on valuing care workers}

Kihlgren 1990, 1996; Williams 1994; Hagen 1995; Matteson 1997; Moniz-Cook 1998; McCallion 1999; Proctor 1999; Wilkinson 1999; Lintern 2000; Wells 2000; Burgio 2002; Magai 2002; Testad 2005; Davison 2007.

\section{The psychiatrist's role in effective training}

All the papers agreed that stand-alone classroom teaching has a limited and very short-lived effect in developing care skills. Effective teaching and 
training require three stages, which have been best described as predisposing, enabling and reinforcing (Green 1980; Davis 1992; Aylward 2003; Featherstone 2004). Psychiatrists can play a role in each of these.

The predisposing stage This first stage involves the communication or dissemination of information designed to modify an individual's knowledge, beliefs and attitudes. It might use, for example, classroom teaching, written information, websites or video presentations. Some psychiatrists in the $\mathrm{UK}$, on an ad hoc or a regular basis, give lectures or seminars to groups that include dementia care workers. This teaching temporarily improves knowledge and attitudes. However, to have a lasting effect on the quality of care, it needs to be coordinated with the other two stages of effective training: enabling and reinforcing. And it is at these subsequent essential stages that all psychiatrists can contribute to developing the skills of dementia care workers.

The enabling stage Enabling involves changing conditions and resources in the work environment so that individuals can implement the new skills they have just learnt. For example, it might mean modifying work schedules or practice opportunities so that dementia care workers can spend more time with each individual. Time is the most commonly described enabling factor in improving dementia care: if care and communication are rushed, the individual will be much less likely to receive good care or to understand the communication. In the case vignette of $\mathrm{Mr} \mathrm{P}$, the psychiatrist and $\mathrm{CPN}$ recommended increasing the amount of time allotted to his personal care

The reinforcing stage In this final stage, carers are given cues or reminders to implement their new skills. These include formal motivation, supervised practice, one-to-one supervision, peer support, advice and feedback. When discussing individuals with carers, healthcare professionals can emphasise the importance of care skills, ensuring that they are set out in individually tailored care plans. Many of the studies we reviewed used external experts to reinforce good practice. Their independence of the day-to-day staff and management structure was found to be more effective in reinforcing good practice (Marsiske 1989; Cohn 1990; Depla 2003). Visiting psychiatrists are in a good position to act as such 'external experts'.

It is unlikely that low-paid care workers will be self-directed learners, seeking out training in their own time and at their own cost. Motivational systems are helpful, especially as the completion of basic dementia training does not usually lead to promotion and increase in salary. A consultant psychiatrist can contribute to this motivational process by praising good care and pointing out the importance of using care skills to minimise behavioural symptoms and reduce the use of antipsychotic medication.

\section{Key studies on psychiatrists' role in effective training Kihlgren 1990, 1996; Feldt 1992; Smyer 1992; Maas 1994; Lintern 1996; Mathews 1997; Matteson 1997; Stevens 1998; McCallion 1999; Proctor 1999; Wilkinson 1999; Burgio 2001, 2002; Roth 2002; Chang 2005; Davison 2007.}

\section{Accessible training}

The authors of all the studies we reviewed emphasised that steps must be taken to ensure that dementia care workers attend training. Training should be provided at a place, time and cost that maximises attendance. Incentives such as protected educational time are essential if these workers are to attend. Compulsory social care training is commonplace in many care homes, and it would be of great value if basic dementia care training were also compulsory. In the scenario of Mr P, the psychiatrist and CPN had an opportunity to suggest to the managers that all the carers, not just the senior ones, and any staff members who had regular direct contact with people with dementia, should have access to basic training. The public display of certificates of attendance at training courses is not sufficient evidence that all current members of staff have received training and that the skills learnt are reinforced day-to-day throughout the care home (Cohn 1990; Stevens 1998; Banazak 2000; Burgio 2001, 2002).

Primary aspects of the strategy for developing care skills are summarised in Box 3 .

BOX 3 Strategic approach to developing care skills

- Acknowledge and recognise the role of dementia care workers

- Support training programmes in meetings and committees

- Support colleagues who are involved in training

- Emphasise the importance of enablement and reinforcement after teaching

- Collaborate with care homes, domiciliary care companies and acute in-patient services

- Ask what training carers have had

- Ask whether all carers have received training 


\section{Teaching methods and training}

All of the studies in our review employed classroom teaching. For psychiatrists who are involved in running specific courses, the following features are more likely to be successful in improving predisposing attitudes, knowledge and skills.

Improved attitudes towards people with dementia can be taught successfully and are as beneficial for their well-being as is their carers' knowledge about the condition. Teaching should be in small groups that are interactive and draw on the carers' own experiences. Didactic teaching should be limited to about 10 minutes at a time, based on the group's experience if possible, and should be broken up with a wide range of activities and opportunities for collaborative discussion.

Many care workers already have a lot of knowledge and understanding of dementia care. If educators patronise and dismiss already established skills, the training can cause more harm than good, by alienating hard-working, effective care staff. Teaching must not be persecutory: people will be put off if they feel that they will lose their jobs if they fail to put into practice perfectly what is being taught. These collaborative principles also apply when discussing individual cases in a clinical setting.

Following this predisposing teaching, the employing organisation must reinforce and enable the skills learnt by providing further on-the-job training, motivational incentives and regular feedback. For psychiatrists attending care homes, discussing residents' personal care with care workers is an excellent opportunity to reinforce person-centred care, communication techniques and how best to support activities of daily living, and the importance of these in reducing the behavioural and psychological symptoms of dementia.

Box 4 highlights primary aspects of constructive teaching and training.

BOX 4 Constructive approach to teaching, training and clinical discussions

- Find out what people know

- Know what has been taught, so that it can be reinforced

- Motivate rather than criticise

- Reinforce and praise good practice

- Avoid lengthy lectures

- Focus on key components of care

- Focus on individual examples rather than theory

\section{Key studies on training methods}

Ripich 1995; Palmer 1996; Cohen-Mansfield 1997; Middleton 1999; Burgio 2001; Peterson 2002; Featherstone 2004; Chang 2005; Parks 2005.

\section{Training content: attitudes, basic knowledge and core skills}

In this section we outline the evidence-based attitudes, basic knowledge and core skills that every care worker should have when providing day-to-day support for individuals with dementia. Any training course should cover in detail the seven areas touched on below. Anyone who claims to be an expert on dementia, irrespective of professional background or status, should aim to teach and reinforce these because there is evidence that this will make a difference to care that people with dementia receive (Box 2).

\section{Attitude}

A positive yet realistic attitude underpins care delivery. Dementia carers should have a positive commitment to approaching and communicating with each individual in an appropriate way, believing that this improves quality of life, sustains independence for longer and reduces the incidence of resistant and aggressive behaviour. They must be realistic and realise that, over time, the progressive nature of dementia leads to greater cognitive impairment, reduced function and increased need. This characteristic of the illness will require changes in the approach and support that they provide. It is important that carers appreciate that dementia is a terminal illness (Wilkinson 1999; Parks 2005).

\section{Care plans}

Individually tailored and person-centred care should be the underlying philosophy of training, where establishing and maintaining the relationship with the individual is given priority. Care plans should be developed to suit individual need, and not for the smooth running of the organisation. Wandering and day/night reversal are the most commonly cited problems of dementia care. Care plans should accommodate these behaviours rather than trying to change them. For example, there should be somewhere safe for individuals to wander, night staff should be educated that patients/residents do not have to sleep from 22.00 to $07.00 \mathrm{~h}$ every night, and wandering and day/ night reversal should not be taken as an immediate indication for sedating, hypnotic or antipsychotic medication The life history of each person should 
be known and used to assist communication and to give value to their day-to-day existence. Every dementia care worker must contribute to the formulation of individual care plans that cover all aspects of the person's life and ensure that they are carried out and modified as circumstances and the clinical picture change.

\section{Key studies on care plans}

Kihlgren 1990, 1996; Ripich 1995; Palmer 1996; Matteson 1997; Middleton 1999; Proctor 1999 Lintern 2000; Wells 2000; Burgio 2001, 2002; Magai 2002; Roth 2002

\section{Activities of daily living}

Skills to support personal activities of daily living, including feeding, bathing, dressing and hairwashing, must be given high priority. It should be emphasised that they can be learnt and developed. Care workers must have the skills necessary to assist in proportion to the abilities of the person for whom they are caring. To sustain the individual's independence for longer, carers should not take over or humiliate during personal care. They must approach by properly knocking on the door and introducing themselves, and present warm and positive facial expressions and body language. They should speak to the individual face to face, always announcing clearly what care is being offered and conducting as much of the care as possible in front of the resident (e.g. running water, getting out toothbrushes or clothes), so that the person can see exactly what is happening and about to happen to them. If care is resisted, the care staff should return later; this is referred to as 're-approaching' (Palmer 1996). The materials necessary for personal care (such as soap, flannels, towels and combs) should be visible, ready for use and clearly the personal property of the individual receiving care. During care, the person must be the focus and private conversations across the individual must be avoided. Carers should use single instructions and comprehensible verbal prompts, allowing adequate time for the person to respond.

\section{Key studies on activities of daily living}

Feldt 1992; Kihlgren 1996; Mathews 1997; Stevens 1998; Lintern 2000; Wells 2000; Burgio 2001, 2002; Peterson 2002; Roth 2002; Chang 2005; Davison 2007.

\section{Day-to-day communication}

Day-to-day communication should be face to face, paced and supported by appropriate, warm, non-verbal cues to confirm that it is a proper interactive exchange. Carers should try to orient individuals using clear cues. They should use repetition and prompts to assist continuity, and try to direct and structure conversations on one topic at a time. Changes in topic should be clearly announced and the individual should be given time to process the change in theme, with repetition if necessary. All sensory impairments should be considered and strenuous efforts made to overcome poor hearing and visual impairment. The environment should be well lit, so that both carers and those they care for can pick up on facial expressions and body language. Carers should speak clearly and avoid words that the individual might not understand. In general conversation, topics that might interest the individual should be chosen, for example events and relationships from their personal history. Patient listening is essential, and all dementia carers must respond to repetition and reality conflicts without resorting to confrontation or reprimand.

\section{Key studies on day-to-day communication}

Kihlgren 1990, 1996; Ripich 1995; Mathews 1997; Lintern 2000; Wells 2000; Burgio 2001, 2002; Magai 2002; Roth 2002.

\section{Medical features of dementia}

A good understanding of the organic, progressive and variable nature of dementia allows staff to have empathy for the broad range of illness symptoms and resist beliefs such as 'She's just putting it on' or 'He should stop behaving like a child'. Dementia does not just cause poor memory, understanding and communication; it also affects appetite, the sleep/wake cycle, mobility and balance. In time, it causes death. Staff should understand that dementia leads to increased vulnerability to environmental factors that is unique to each individual.

\section{Key studies on medical features of dementia}

Smyer 1992; Cohen-Mansfield 1997; Middleton 1999; Lintern 2000; Rosen 2002; Featherstone 2004; Parks 2005.

\section{Non-pharmacological strategies for difficult} behaviour

Understanding difficult behaviour from the perspective of theindividual and not the convenience of care teams or institutional expectations is the cornerstone on which non-pharmacological care strategies are based. Teaching carers to see aggressive behaviour as a response to threat or to loss of routine, dignity or relationships allows them to make necessary adjustments to an individual's routines and environment that reduce 
the distressing behaviours. All aggression and resistance to care, even the most minor, should be reported early and discussed so that they can be understood. Care workers should feel confident that early reporting of minor incidents will not get the individual or themselves into trouble; rather, it should allow the problem to be addressed through adjustment of care plans. Early reporting has been shown to reduce serious incidents (Palmer 1996). Careful control of the environment can make a huge difference to the quality of life of people with dementia. Ensuring that furnishings, lighting and signs are easy to use and navigate reduces the chance of confusion and distress. Staff should ensure that each individual's personal effects are accessible and returned to them if removed for any reason.

From their first day, carers should be taught that drugs such as benzodiazepines and antipsychotics are a last resort, not a first choice.

\section{Key studies on non-pharmacological strategies}

Marsiske 1989; Williams 1994; Hagen 1995;

Palmer 1996; Matteson 1997; Moniz-Cook 1998;

Middleton 1999; Wilkinson 1999; Wells 2000;

Testad 2005.

The emotional demands and rewards of dementia care

It is important to teach staff about the emotional demands and rewards of dementia care. In particular, staff need to be honest with themselves and others about the feelings provoked by people with dementia. This reflective approach can improve performance and job satisfaction and reduce staff turnover.

Key studies on the emotional demands and rewards of dementia care

Feldt 1992; McCallion 1999; Wells 2000; Magai 2002.

The attitudes, knowledge and skills required of dementia carers are summarised in Box 5 .

\section{Conclusions}

One of the priority objectives of the UK's National Dementia Strategy is to create an informed and effective workforce for people with dementia (Department of Health 2009: p. 28). In their role as clinical leaders in multi-agency services, psychiatrists for older adults can contribute to achieving this goal. As clinicians seeing patients with dementia in community settings, they can ensure that individual care plans are suitable
BOX 5 Basic attitude, knowledge and skills

All dementia care workers should

- have a positive yet realistic attitude

- contribute to the development and delivery of individually tailored care plans

- support activities of daily living at a level and in a way appropriate for each individual

- communicate effectively with each individual

- understand the organic and progressive nature of dementia

- apply non-pharmacological strategies for difficult behaviour, including determining predisposing factors and proper reporting

- reflect on the emotional demands of dementia care

and delivered well. As experts contributing to the organisation and planning of multi-agency services, they can support the development of care workers' skills.

Our systematic review of the literature has identified employers' strategies, educational methods, attitudes, basic knowledge and skills for dementia care workers that have been shown to improve day-to-day dementia care. Psychiatrists directly involved in dementia care training should be aware of how to sustain the results of classroom teaching in practical care. They should be asking whether paid carers have had core dementia training, particularly when they are assessing individuals with behavioural and psychological symptoms of dementia. Equally, they should be able to inform care homes, domiciliary care companies and ward managers what constitutes evidence-based core dementia training.

\section{References}

Aylward S, Stolee P, Keat N, et al (2003) Effectiveness of continuing education in long term care: a literature review. Gerontologist 43: 259-71

Banazak DA, Mickus M, Averill M, et al (2000) Herding cats: barriers to implementing a nurse aide educational program. Annals of Long Term Care 8: $68-71$.

Burgio LD, Allen-Burge R, Roth DL, et al (2001) Come talk with me: improving communication between nursing assistants and nursing home residents during care routines. Gerontologist 41: 449-60.

Burgio LD, Stevens A, Burgio KL, et al (2002) Teaching and maintaining behaviour management skills in the nursing home. Gerontologist 42 : 487-96.

Centre for Evidence Based Medicine (2009) Oxford Centre for Evidence Based Medicine - Levels of Evidence (March 2009). CEBM (http://www. cebm.net/index.aspx? $=1025$

Chang CC, Wykle M, Madigan EA (2005) The effect of feeding skills training programme for nursing assistants who feed dementia patients in Taiwanese nursing homes. Geriatric Nursing 27: 229-37. 
Cohen-Mansfield J, Werner P, Culpepper WJN, et al (1997) Evaluation of an in service training programme on dementia and wandering. Journal of Gerontological Nursing 23: 40-7.

Cohn M, Horgas AL, Marsiske M (1990) Behaviour management training for nurse aides: is it effective? Journal of Gerontological Nursing 16: 21-5.

Davis D, Thomson M, Oxman AD, et al (1992) Evidence for the effectiveness of CME: a review of 50 randomized trials. JAMA 268: $1111-7$.

Davison TE, McCabe MP, Visser S, et al (2007) Controlled trial of dementia training with a peer support group for aged care staff. International Journal of Geriatric Psychiatry 22: 868-73.

Department of Health (2009) Living Well with Dementia: A National Dementia Strategy. Implementation Plan. Department of Health (http://www.dh.gov.uk/prod_consum_dh/groups/dh_digitalassets/ documents/digitalasset/dh_103136.pdf).

Depla MFIA, Pols J, De Lange J, et al (2003) Integrating mental health care into residential homes for the elderly: an analysis of six Dutch programmes for older people with severe and persistent mental illness. Journal of the American Geriatrics Society 51: 1275-7.

Draper B, Low L (2004) What is the Effectiveness of Old-Age Mental Health Services? (Health Evidence Network Report). WHO Regional Office for Europe (http://www.euro.who.int/document/E83685.pdf).

Featherstone K, James IA, Powell I, et al (2004) A controlled evaluation of a training course for staff who work with people with dementia. Dementia 3: 181-94.

Feldt KS, Ryden MB (1992) Aggressive behaviour: educating nursing assistants. Journal of Gerontological Nursing 18: 3-12.

Green L, Kreuter M, Deeds S, et al (1980) Health Education Planning: A Diagnostic Approach. Mayfield Press.

Grol R, Grimshaw J (2003) From best evidence to best practice: effective implementation of change in patient's care. Lancet 362: 1225-30.

Hagen BF, Sayers D (1995) When caring leaves bruises: the effects of staff education on resident aggression. Journal of Gerontological Nursing 21: 7-16.

Kihlgren M, Hallgren A, Norberg A, et al (1990) Effects of the training of integrity-promoting care on the interaction at a long-term ward. Analysis of video-recorded social activities. Scandinavian Journal of Caring Sciences 4: 21-8.

Kihlgren M, Hallgren A, Norberg A, et al (1996) Disclosure of basic strengths and basic weaknesses in demented patients during morning care, before and after training: analysis of video recordings by means of Erikson theory 'eight stages of man'. International Journal of Aging and Human Development 43: 219-33.

Kuske B, Hanns S, Luck T, et al (2007) Nursing home staff training in dementia care: a systematic review of evaluated programs. International Psychogeriatrics 19: 818-41.

Lintern T. Woods B (1996) The dementia care practitioner assessment. Journal of the British Association for Service to the Elderly 63: 12-8.

Lintern T, Woods B, Phair L (2000) Before and after training: a case study of intervention. Journal of Dementia Care 8: 15-7.

Livingston G, Johnston K, Katona C, et al (2005) Systematic review of psychological approaches to the management of neuropsychiatric symptoms of dementia. American Journal of Psychiatry 162: 19962021

Maas M, Buckwalter KC, Swanson E, et al (1994) Training key to job satisfaction. Journal of Long Term Care Administration 22: 23-6.

Magai C, Cohen Cl, Gomberg D (2002) Impact of training dementia caregivers in sensitivity to nonverbal emotion signals. International Psychogeriatrics 14: 25-38.

Marsiske M, Horgas AL, Cohn MD (1989) Evaluation of a behavior management training program for nursing home caregivers. Poster presentation at the 1989 American Society on Aging Conference, Washington, DC (http://eric.ed.gov/PDFS/ED312596.pdf).
Mathews RM, Altman H (1997) Teaching nurse aides to promote independence in people with dementia. Journal of Clinical Geropsychology 3: 149-56.

Matteson MA, Linton AD, Cleary BL, et al (1997) Management of problematic behavioural symptoms associated with dementia: a cognitive developmental approach. Aging - Clinical and Experimental Research 9: 342-55

McCallion P, Toseland RW, Lacey D, et al (1999) Educating nursing assistants to communicate more effectively with nursing home residents with dementia. Gerontologist 39: 546-58.

Middleton H, Keene RG, Johnson C, et al (1999) Physical and pharmacological restraints in long term care facilities. Journal of Gerontological Nursing 25: 26-33.

Moniz-Cook E, Agar S, Silver M, et al (1997) Residential care for older people: job satisfaction and psychological health in care staff. Health and Social Care in the Community 5: 124-33.

Moniz-Cook E, Agar S, Silver M (1998) Can staff training reduce carer stress and behavioural disturbance in the elderly mentally ill? International Journal of Geriatric Psychiatry 13: 149-58.

Moniz-Cook E, Woods R, Gardiner E (2000) Staff factors associated with perception of behaviour as challenging in residential and nursing homes. Aging \& Mental Health 4: 48-55.

Palmer AC, Withee BM (1996) Dementia care: effects of behavioural intervention training on staff perceptions of their work in veterans' nursing home. Geriatric Nursing 17: 137-40.

Parks SM, Haines C, Foreman D, et al (2005) Evaluation of an educational programme for long term care nursing assistants. Journal of American Medical Directors Association 6: 61-5.

Peterson D, Berg-Weger M, McGillick J, et al (2002) Basic care. I: The effect of dementia-specific training on certified nursing assistants and other staff. American Journal of Alzheimer's Disease and Other Dementias 17: 154-64.

Proctor R, Burns A, Powell HS, et al (1999) Behavioural management in nursing and residential homes: a randomised controlled trial. Lancet 354: 26-9.

Ripich DN, Wykle M, Niles S (1995) Alzheimer's disease caregivers: the FOCUSED program. Geriatric Nursing 16: 15-9.

Rosen J, Mulsant B, Kollar M, et al (2002) Mental health training for nursing staff using computer based interactive video: a 6 month randomised trial. Journal of the American Medical Directors Association 3: 291-6.

Roth DL, Stevens A, Burgio LD, et al (2002) Timed event sequential analysis of agitation in nursing home residents during personal care interactions with nursing assistants. Journals of Gerontology Series B: Psychological Sciences and Social Sciences 57: 461-8.

Smyer M, Brannon D, Cohn M (1992) Improving nursing home care through training and job redesign. Gerontologist 32: 327-33.

Stevens A (1998) Teaching and maintaining behaviour management skills with nursing assistants in a nursing home. Gerontologist 38 : 379-84.

Testad I, Aasland AM, Aarsland D (2005) The effect of staff training on the use of restraint in dementia: a single blind randomised controlled trial. International Journal of Geriatric Psychiatry 20: 587-90.

Wells DL, Dawson P, Sidani S, et al (2000) Effects of an abilitiesfocused program on morning care on residents who have dementia and on caregivers. Journal of the American Geriatric Society 48: 442-9.

Wilkinson CL (1999) An evaluation of an educational program on the management of assaultative behaviours. Journal of Gerontological Nursing 25: 6-11.

Williams DP, Wood EC, Moorleghen F (1994) An in-service workshop for nursing personnel on the management of catastrophic reactions in dementia victims. Clinical Gerontologist 14: 47-54.

\section{MCO answers \\ 1 b 2 e 3 b 4 a 5 e}




\section{MCOs}

Select the single best option for each question stem

1 Enabling dementia care workers to provide good care in a care home would include:

a showing them a video about the pathology of dementia

b ensuring they had enough time in the morning to get the residents up without rushing and allowing residents to do as much of their own care as they can

c supervising them feeding a resident

d giving them a book about helping people with dementia with their activities of daily living

e asking them to support several residents with advanced dementia at meal times so that they gain a lot of experience quickly.

2 Reinforcing good-quality dementia care in a care setting would include:

a surfing the internet for sites on managing dementia

b attending a class on diversity c ensuring that bedrooms are properly lit so a person with dementia could see clearly to do up their buttons

d inviting a consultant psychiatrist to give a lecture on Alzheimer's disease

e financial incentives for care workers who give high-quality care.

3 There is evidence to support training dementia care workers in the following skills:

a cognitive-analytic therapy

b maintaining the skills of individuals with dementia while prompting personal care

c ethical use of covert medication

$d$ forceful and effective use of control and restraint

e checking drug cards for errors.

4 During day-to-day communication, people with dementia understand better if carers:

a are familiar with their life stories b shout at them

c talk face to face but avoid eye contact

$\mathrm{d}$ talk with exaggerated and amusing facial expressions

e test them on what was said to them yesterday.

5 While supporting the personal activities of daily living, dementia care workers can make it a more enjoyable experience, increase the chance of cooperation and reduce the risk of resistance to care by:

a focusing on completing care quickly, to reduce embarrassment

b doing all fiddly things such as buttons, zips, clips and brooches for patient/client

c explaining the next three steps of care to the patient/client before they begin

d just quickly doing up someone's buttons if they are struggling - to avoid embarrassment rather than asking whether they would like help e giving the individual adequate time to respond to prompts. 